\title{
(- OPEN ACCESS \\ Could the rise in mortality rates since 2015 be explained by changes in the number of delayed discharges of NHS patients?
}

\author{
Mark A Green, ${ }^{1}$ Danny Dorling, ${ }^{2}$ Jonathan Minton, ${ }^{3}$ Kate E Pickett ${ }^{4}$
}

\begin{abstract}
'Department of Geography and Planning, University of Liverpool, Liverpool, UK

${ }^{2}$ School of Geography and the Environment, University of Oxford, Oxford, UK

${ }^{3}$ School of Social and Political Sciences, University of Glasgow, Glasgow, UK

${ }^{4}$ Department of Health Sciences, University of York, York, UK
\end{abstract}

\section{Correspondence to}

Dr. Mark A Green, Department of Geography and Planning, University of Liverpool, Roxby Building, Liverpool, L69 7ZT, UK mark.green@liverpool.ac.uk

Received 1 May 2017 Revised 12 August 2017

Accepted 25 August 2017 Published Online First 23 September 2017

\section{Q Croshark}

To cite: Green MA, Dorling D, Minton J, et al. J Epidemiol Community Health 2017;71:1068-1071.

\section{ABSTRACT}

Background 2015 saw the largest annual spike of mortality rates in England in almost 50 years. We examine whether these changes in mortality rates are associated with an indicator of poor functioning of health and social care: delay in hospital discharges. Methods Office for National Statistics monthly data of death counts and mortality rates for the period August 2010-March 2016 were compared with delays in discharges from National Health Service (NHS) England data on transfers of care for acute and non-acute patients in England. Autoregressive Integrated Moving Average regression models were used in the analysis. Results We estimate that each additional day an acute admission was late being discharged was associated with an increase in 0.394 deaths $(95 \% \mathrm{Cls} 0.220$ to 0.569). For each additional acute patient delayed being discharged, we found an increase of 7.322 deaths (95\% Cls 1.754 to 12.890). Findings for non-acute admissions were mixed.

Conclusion The increased prevalence of patients being delayed in discharge from hospital in 2015 was associated with increases in mortality, accounting for up to a fifth of mortality increases. Our study provides evidence that a lower quality of performance of the NHS and adult social care as a result of austerity may be having an adverse impact on population health.

\section{INTRODUCTION}

The period July 2014 to June 2015 saw an additional 39074 deaths in England and Wales compared with the same period the previous year. ${ }^{1}$ While mortality rates fluctuate year-on-year, this was the largest rise for nearly 50 years and the higher rate of mortality has been maintained throughout 2016 and into $2017 .^{2}$ These recent trends contrast with the long-term decline in age-specific mortality rates throughout the 20th and 21 st centuries. ${ }^{3}$ The majority of these additional deaths were in frail elderly individuals. ${ }^{14}$

The increase in mortality rates has occurred during a crisis in the National Health Service (NHS). The number of NHS trusts with budget deficits has increased sharply since $2014 / 2015,{ }^{5}$ as did waiting periods for elective surgery in $2015 .^{6}$ Issues within the NHS are being compounded by problems with the provision of adult social care to support individuals leaving NHS care ${ }^{7}$ and pressures of increased demand. ${ }^{8}$

We examine whether increases in the number of individuals who are delayed being discharged from hospital are associated with changes in the number of deaths. Delayed discharges may signal worsening health and social care and influence mortality rates through delaying transfer to appropriate care and/ or preventing new patients from accessing appropriate care.

\section{METHODOLOGY}

Using data on monthly number of deaths, ${ }^{2}$ we calculated mortality rates. Monthly population counts are not produced so we used midyear population estimates for England. ${ }^{9}$ Official estimates are produced for the total population count on 31 June and were available up to mid-2015 at the time of analysis. We then used population projection estimates for periods outside of this period pro rata for month. ${ }^{10}$ While mortality rates are our primary outcome, we also test the monthly number of deaths since our population data are estimates and may introduce bias into our results.

The monthly number of delayed transfers of care was used as our explanatory variable. ${ }^{11}$ A delayed transfer of care was defined as where an admitted patient was ready to be discharged from the care they were receiving but was still occupying a bed. Two measures were available: the total number of patients (defined as the number of patients currently identified as being delayed on the last Thursday of each month) and the total number of cumulative days per month patients were delayed. Delayed discharges were also split by acute and non-acute admissions to account for patient mix in severity. We used data for the months August 2010 to March $2016(n=68)$, the latest available at the time of analysis.

Due to the time-series nature of the data, we use an Autoregressive Integrated Moving Average (ARIMA) regression model to examine the number of deaths for each month. ARIMA models account for the temporal interdependence of observations using a series of lagged variables of the outcome variable (ie, 1 month's observations are predictive of the following month) and error terms (observations are non-independent). ARIMA thus provides a fairer estimation of the association of mortality rates to our exposures. Models were selected based on the 'auto.arima' $\mathrm{R}$ function, which selects the model that best fits the data. ${ }^{12}$ We included a seasonal element in the model to account for the fact that mortality rates are highest in winter and lowest in summer. The model selected was: $\operatorname{ARIMA}(0,0,0)(1,1,0)_{12}$ with drift. 

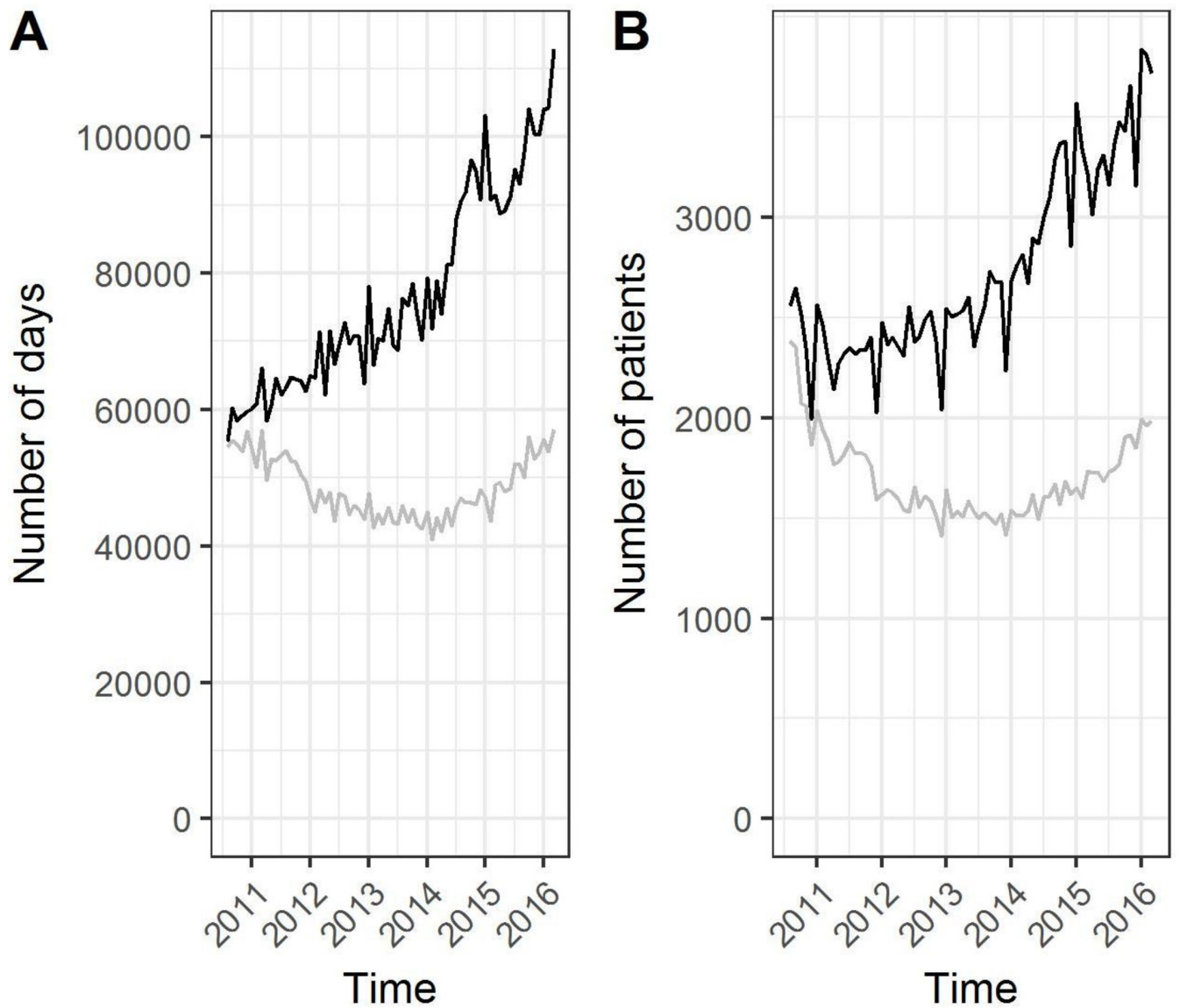

\section{Acute - Non-Acute}

Figure 1 Time-series data of hospital admissions that had delayed discharges by acute and non-acute (monthly data 2010-2016): (A) total number of days experienced by patients and (B) total number of patients.

Ethical approval was not required for this analysis of openly available secondary data.

\section{RESULTS}

From 2011, there is an upward trend in the total number of days acute patients experienced delays in their discharges, although not for the total number of acute patients (figure 1). The rate of this increase appears to change in 2014, where both measures begin to trend upwards. The trend for non-acute admissions differs with a 'u'-shaped trend of declines up to 2014 and increases therein after for both measures.

Table 1 presents the results from four separate regression models. Model A uses the total number of deaths within a month as the outcome variable and examines the total number of days cumulatively patients were late being discharged. We find a positive association with the total number of days delayed that were acute admissions. For each additional day an acute admission was late being discharged, we estimate that the number of deaths increased by 0.394 (95\% CIs 0.220 to 0.569 ). We also detect a negative association for non-acute admissions.

Model B repeats the same analysis with a different exposure: the total number of patients who were late being discharged. The results show similar trends to those reported in model A but with greater uncertainty. Each one unit increase in the number of acute patients who were delayed being discharged was associated with an increase in the total number of deaths of $7.322(95 \%$
CIs 1.754 to 12.890 ). For non-acute admissions, we also find a negative association.

Models C and D repeat the same analyses presented in models $\mathrm{A}$ and $\mathrm{B}$ but with mortality rate used as the outcome variable. Both models (C and D) demonstrate positive associations for acute admissions. While the associations for non-acute admissions were also negative, the $95 \%$ CIs cross a value of 0 and hence were non-significant.

\section{DISCUSSION}

Our analysis shows that changes in the numbers of delayed discharges were associated with changes in mortality trends for England. Delays in the discharge of acute patients were consistently positively associated with a higher monthly number of deaths and overall mortality rates across each of our models; associations for non-acute delayed discharges were mixed. We interpret the model coefficients to suggest that around one-fifth of the observed increase in mortality between 2014 and 2015 could be due to changes in the numbers of acute patients delayed being discharged.

We hypothesise two possible mechanisms through which delayed discharges may lead to increases in mortality rates: First, patients who are delayed being discharged may be postponed in accessing the correct type of care. Delays may also result in stress and anxiety among individuals who wish to be discharged. One criticism of this hypothesis is that individuals are still receiving care, although 
Table 1 Results from our time-series regression analyses analysing whether delayed discharges were associated with the total number of deaths

\begin{tabular}{|c|c|c|c|}
\hline & Coefficient & Lower $\mathrm{Cl}$ & Upper Cl \\
\hline \multicolumn{4}{|c|}{ (A) Outcome: total number of deaths } \\
\hline \multicolumn{4}{|c|}{ Exposure: total number of days patients were late being discharged } \\
\hline Acute admissions & 0.394 & 0.220 & 0.569 \\
\hline Non-acute admissions & -0.244 & -0.433 & -0.056 \\
\hline SAR1 & -0.468 & -0.720 & -0.215 \\
\hline Drift & -238.806 & -372.365 & -105.248 \\
\hline AIC & 1060.67 & & \\
\hline \multicolumn{4}{|c|}{ (B) Outcome: total number of deaths } \\
\hline \multicolumn{4}{|c|}{ Exposure: total number of patients who were late being discharged } \\
\hline Acute admissions & 7.322 & 1.754 & 12.890 \\
\hline Non-acute admissions & -6.020 & -12.025 & -0.015 \\
\hline SAR1 & -0.495 & -0.738 & -0.252 \\
\hline Drift & -118.677 & -252.577 & 15.224 \\
\hline AIC & 1071.46 & & \\
\hline \multicolumn{4}{|c|}{ (C) Outcome: mortality rate (per 100000 ) } \\
\hline \multicolumn{4}{|c|}{ Exposure: total number of days patients were late being discharged } \\
\hline Acute admissions & 0.0007 & 0.0003 & 0.0011 \\
\hline Non-acute admissions & -0.0005 & -0.0010 & 0.0001 \\
\hline SAR1 & -0.4648 & -0.7208 & -0.2087 \\
\hline Drift & -0.4845 & -0.7401 & -0.2290 \\
\hline AIC & 356.45 & & \\
\hline \multicolumn{4}{|c|}{ (D) Outcome: mortality rate (per 100000 ) } \\
\hline \multicolumn{4}{|c|}{ Exposure: total number of patients who were late being discharged } \\
\hline Acute admissions & 0.013 & 0.003 & 0.024 \\
\hline Non-acute admissions & -0.011 & -0.022 & 0.000 \\
\hline SAR1 & -0.494 & -0.737 & -0.251 \\
\hline Drift & -0.264 & -0.513 & -0.016 \\
\hline AIC & 366.92 & & \\
\hline
\end{tabular}

AIC, Akaike Information Criterion; SAR1, Seasonal AutoRegressive coefficient of order 1 .

this does not account for the wider context of cuts to services that may limit quality of care. Longer stays within hospital may expose patients to inadequate care, although they may equally delay exposure to inadequate social care due to cut backs.

Second, delays in discharging patients out of hospital may have knock-on effects on individuals outside of hospitals. A lack of available beds in hospitals due to blockages in discharging patients will harm those who have yet to be admitted and are in need of medical care. Given that we observe a stronger association for discharge delays among acute patients compared with non-acute patients, the hypothesis appears plausible since acute patients are likely to require urgent care.

These explanations are unlikely to completely account for the rise in mortality rates, and delayed discharges could be a symptom of the broader funding crises in the NHS and adult social care, ${ }^{57}$ which have resulted in cutbacks to: the availability and quality of service provision including; declining ambulance response times, ${ }^{13}$ increased general practitioner workloads ${ }^{14}$ and increased waiting times. ${ }^{6} 1516$ Such issues may have begun to have a knock-on effect on population health.

Alternative explanations for the rise in mortality rates include: the effects of an ageing population, influenza and random fluctuations. None of these explanations appear to fully explain trends in mortality. ${ }^{15}$ It is also plausible that the wider context of austerity has created conditions for enabling or compounding their impacts. For example, having a large population share of elderly people may put greater pressure on health and social care, but issues will only arise if these services are underfunded or operate inefficiently.

There are several limitations to our study. Our analyses are observational and associational, so they are limited in their ability to draw out causal inferences. We lack adjustment for other covariates in our model due to the absence of available data (partly due to the very recent release of the data). Our results should be interpreted cautiously; the study was exploratory in nature but offers a useful starting point for further analysis. We also use population-level data and therefore cannot detect whether delayed discharges for particular individuals actually led to deaths.

In conclusion, we have shown that the increasing prevalence of delayed discharges within hospitals occurred as mortality rates rose in England. Despite the exploratory nature of our study, the

\section{What is already known on this subject}

2015 saw the largest annual increase in mortality rates for almost 50 years, and mortality rates have remained high since. During the same period, there have been funding crises and poorer quality of care within the National Health Service (NHS) and adult social care. 


\section{What this study adds}

We demonstrate a positive association between the number of acute patients delayed in being discharged, and the cumulative amount of time acute patients were delayed, to the monthly number of deaths and mortality rate. Our results present evidence that a lower quality of performance between the NHS and adult social care may explain part of the increases in mortality rates experienced in England from at least 2015 and onwards.

implications of our findings are important and require urgent attention. Greater investment in the NHS and adult social care to address the rising levels of delayed discharges may be needed to tackle the rapid rise in mortality rates.

Twitter@markalangreen @dannydorling @JonMinton @ProfKEPickett

Contributors MAG designed the study, acquired the data and undertook the analyses. DD and JM contributed to refining the analyses. All authors drafted the manuscript and approved its publication.

Competing interests None declared.

Ethics approval Not required.

Provenance and peer review Not commissioned; externally peer reviewed.

Data sharing statement All data are openly available, and web links to the data have been made throughout.

Open Access This is an Open Access article distributed in accordance with the Creative Commons Attribution Non Commercial (CC BY-NC 4.0) license, which permits others to distribute, remix, adapt, build upon this work non-commercially, and license their derivative works on different terms, provided the original work is properly cited and the use is non-commercial. See: http://creativecommons.org/ licenses/by-nc/4.0/

(c) Article author(s) (or their employer(s) unless otherwise stated in the text of the article) 2017. All rights reserved. No commercial use is permitted unless otherwise expressly granted.

\section{REFERENCES}

1 Green M, Dorling D, Minton J. The Geography of a rapid rise in elderly mortality in England and Wales, 2014-15. Health Place 2017;44:77-85.

2 ONS. Monthly figures on deaths registered by area of usual residence [Internet]. 2017 https://www.ons.gov.uk/peoplepopulationandcommunity/birthsde athsandmarriages/deaths/datasets/monthlyfiguresondeathsregisteredbyar eaofusualresidence

3 Minton J, Vanderbloemen L, Dorling D. Visualizing Europe's demographic scars with coplots and contour plots. Int J Epidemiol 2013:42:1164-76.

4 Hiam L, Dorling D, Harrison D, et al. Why has mortality in England and Wales been increasing? An iterative demographic analysis. J R Soc Med 2017;110:153-62.

5 Dunn P, McKenna H, Murray R. Deficits in the NHS 2016 [Internet]. 2016 http://www. kingsfund.org.uk/sites/files/kf/field/field_publication_file/Deficits_in_the_NHS_Kings_ Fund_July_2016_1.pdf

6 Patients Association. Feeling the Wait [Internet]. 2016. https://www. patientsassociation.org.uk/wp-content/uploads/2016/11/Waiting-Times-Report-2016-Feelingthe-wait.pdf

7 ADASS. ADASS Budget Survey 2016 [Internet]. 2016. https://www.adass.org.uk/ media/5379/adass-budget-survey-report-2016.pdf

8 Care Quality Commission. The state of health care and adult social care in England 2015/16 [Internet]. 2016. http://www.cqc.org.uk/sites/default/files/20161019 stateofcare1516_web.pdf

9 ONS. Population Estimates for UK, England and Wales, Scotland and Northern Ireland [Internet]. 2016. https://www.ons.gov.uk/peoplepopulationandcommunity/populat ionandmigration/populationestimates/datasets/populationestimatesforukenglandan dwalesscotlandandnorthernireland

10 ONS. Table A1-4, Principal Projection - England Summary [Internet]. 2015. https:// www.ons.gov.uk/peoplepopulationandcommunity/populationandmigration/population projections/datasets/tablea14principalprojectionenglandsummary

11 NHS England. Delayed transfers of care, 2017.

12 Hyndman RJ, Khandakar Y. Automatic Time Series Forecasting: The forecast Package for R. J Stat Softw 2008;27:3.

13 NHS England. Ambulance Quality Indicators. 2017. https://www.england.nhs.uk/ statistics/statistical-work-areas/ambulance-quality-indicators/

14 lacobucci G. GPs' workload climbs as government austerity agenda bites. BMJ 2014;349:94300.

15 Hiam L, Dorling D, Harrison D, et al. What caused the spike in mortality in England and Wales in January 2015? J R Soc Med 2017:110:131-7.

16 House of Commons. Briefing paper. NHS Indicators: England [Internet]. 2017. http:// researchbriefings.files.parliament.uk/documents/CBP-7281/CBP-7281.pdf 